\title{
Usage Tourism Websites; An Formative Measurement on Technology, Organization, Environment (TOE) Model in Indonesia
}

\author{
Vera Pujani ${ }^{1}$, Meuthia ${ }^{1}$, Yulia Hendri Yeni ${ }^{1}$, Erna Widyastuti $^{2}$, and Thatok Asmuni ${ }^{3}$ \\ \{ verapujiani@eb.unand.ac.id, meuthia@eb.unand.ac.id, yuliahendriyeni@eb.unand.ac.id, \\ ernalombok@yahoo.com, asmony@yahoo.co.id \}
}

Department of Management, Andalas University, Kampus Unand Limau Manih, Padang, Indonesia ${ }^{1}$; Department of Accounting, Mataram University, Mataram, Indonesia² ${ }^{2}$ Department of Management, Mataram University, Indonesia ${ }^{3}$

\begin{abstract}
The study aims to investigate the influence of TOE (Technological Organizational Environmental) framework among Small Medium-sized Tourism Enterprises (SMTEs) using formative measurement. The composition of TOE is formed by perceived benefit, cost, compatibility, information intensity, the conversance of the $\mathrm{CEO}$, the newfangledness of the CEO, competition, the pressure of the customers or the suppliers, and support from technology merchants. An online-based questionnaire survey was organized by a-91 firm of the tourism sector. The data were analyzed by employing formative measurement model through SEM/PLS technique. The research result shows that technological and environmental aspect becomes the most significant construct towards adoption model rather than organizational aspect. Implications of these results are discussed.
\end{abstract}

Keywords: TOE, Formative, Adoption Model, SEM/PLS

\section{Introduction}

The usage of website in toursim sectors are identified as the fastest growing service-based industry in line with the evolvement of the information and technology of communications [1]. The majority of the tourism company including hotels, car rentals and tour operators are using the internet technology in operating their business through the company's website is believed to be able to improve the communication and create the alternative distribution channel [2][3]. Another research toward the benefit of e-tourism adoption was studied by Dargah and Golrokhsari [4] found that E-tourism can build the convenience for the tourists in term of time efficiency, purchase in whenever and wherever, and direct access information and thus created customers satisfaction. In brief, adopting website presence of the tourism industry is identified as necessity. However, the fact is the research that can be used as references is affiliated to the study of E-tourism adoption especially in developing countries which are still limited rather than in developed countries [5].

Additionally, the research findings of developed countries are not able to be applied directly to the developing countries contexts and the differences are not only from technology, organiztion but also environment (TOE) including cost, economic standpoint, political concern, environmental, social, and cultural factors [6]. Thus, any research regarding e- 
tourism adoption employing TOE model is really needed to support the development of tourism industry in developing countries in the last decades, and also Internet has significantly changed many industries.

Based on the above explanation, this study is designed to examine the influence of TOE framework towards e-tourism adoption in Indonesia. In this case, Bali, Indonesia was selected as the place where the research was conducted. Bali was chosen since in the sustainable tourism and economic development planning under the corridor approach has put tourism in Java - Bali - Nusa Tenggara corridor in the focus; it means the existing development achievement in Java and Bali are going to be intensified and extended further to the East (Nusa Tenggara) [7]. This approach is meant to accelerate economic development in which tourism is considered as potential contributor. Hence, companies that run business within tourism industry in Bali may choose to complete this research.

E-tourism adoption model is developed in this research is adopted from Tomatzky, Fleischer, and Chakrabarti [8] of Technology, Organization, and Environment (TOE) framework. The framework of TOE is chosen based on certain deliberations. Inherently, the framework of TOE has been broadly noticed by previous studies as a deep-rooted framework through which to study the adoption of e-commerce ([5][6][9][10]). In the following section, TOE framework which focus on technological, organizational, and environmental in e-tourism context is presented [11].

\section{Literature Review}

\subsection{E-Tourism}

E-tourism is identified as one of the e-commerce activity in undertaking business transaction of tourism sectors [2]. There is the transformation of value chain process in tourism, culinary, hotel, also hospitality industries could be reflected by tourism transaction via the Internet. E-tourism creates the opportunity for travellers to be able accessing reliable and accurate information, as well as the possibility of making reservations or bookings in fewer time with less expenses and inconvenience than required by conventional methods [1].

Adoption of technological innovation like e-tourism application in the company is considered as a multi-stage process since it requires some changes toward the business process. Owners or managers hold the importance role as facilitators of these changes and as decision makers to adopt new technology. The adoption of e-tourism was grouped into several levels by prior researchers [12][13][14]. Rogers [13] categorized the adoption level of etourism based on the level of firm's innovativeness (i.e. inventors, early adopter, early majority, late majority, and idlers). Teo and Pian [12] also summarized e-commerce adoption into five levels consist of adoption of e-mail, the presence of Internet, prospecting, integration of business, and transformation of business.

\subsection{Technological, Organizational, and Environmental (TOE) Framework}

Tornatzky, Fleischer, and Chakrabakti [8] has been initially developed the framework of TOE. This framework includes three aspects of the context of the firms that influence website adoption such as; technological context, organizational context, and environmental context. In addition, TOE is also compatible with Diffusion of Innovation (DOI) by Rogers (1995) 
focusing on the organization, and technological characteristics in identifying the new technology diffusion [15]. In short, the technological context is related to both external and internal technologies that are accordant to the certain company, since related to the organizational context, the nature and the resources of its companies. Besides that, the environmental context appertains to other parties that surround the firms like competitors, suppliers, and government as well [5].

\subsubsection{Technological Context}

Technological context expresses both internal and external technologies that are accordant to the firm. This encompasses the availability of internal technologies or current practice and equipment that owned by the firm and also the availability of technologies in the market [16]. Ramdani et al suggested that higher impact on e-commerce adoption in SME's derived from technological aspect [17]. This statement was supported by the finding of his research in 2013, where technological context has a high influence in e-commerce adoption. They found that every indicator of technological context - perceived benefit, compatibility and cost has significant influence on e-commerce adoption by SMEs.

Thus, based on previous studies above, the following hypothesis is stated:

H1: Technological context has significant influence on the adoption of e-tourism by companies

\subsubsection{Organizational Context}

The second dimension of TOE framework is organizational context. This context can be recognized affect the adoption of SME's applications and factors in organization context that look to be the primal focus of many studies in SMEs [17]. Organizational context relates to the characteristics of the firms that might affect the e-commerce adoption. According to Molla and Licker [18], when making decisions Perceived E-readiness Model (PERM) is necessary to adopt e-commerce by defining perceived e-readiness as the assessment of organization upon innovational, managerial, organizational, and environmental conditions. Similar with TOE framework, PERM model contains two types of construct: POER and PEER. POER reffered to perceived organizational e-readiness, meanwhile PEER is known as perceived external ereadiness. Molla and Licker [19] also found that there are several organizational factors especially such as human, business, and technological resources and awareness are more dominant than environmental factors in the initial e-commerce adoption.

Regarding organizational context, Ramdani et al [17] supported the finding from Molla and Licker [19] that organizational characteristics have high impact on e-commerce adoption. Also, Ghobakhloo research finding support above statement. Organizational context with indocators of information intensity, the coversance of CEO, and newfangledness significantly influence the e-commerce adoption. Thus, based on the previous studies above, this following hypothesis is stated:

H2: Organizational context has significant influence on the adoption of e-tourism by companies

\subsubsection{Environmental Context}

The last context in TOE Model is environmental context which refers to the arena where the organizations do the business. IT innovations do not accomodate only for an internal audience, but also to company's customers, suppliers, and business partners [20]. 
Organization's inclination to innovate is also triggered by environmental opportunities and threats [21]. Then another study argued that alteration toward Information System could be a respond to an event or this alteration has its causation in the pressure from customers and a prominence in imroving the efficiency, as well as the pressure from both the internal and external environment [15].

Environmental aspect can be claimed to have a high impact on SME's adoption of EA [17]. As explained above, Molla and Licker proposed PEER Model. PEER referred to the extent in which managers believed that the market forces, the governmrnt, and other supporting industries were all set to support the e-commerce implementation of the organizations. Moreover, PEER expresses the assessment of an organization and the evaluation of accordant factors of external environmental (envrionmental imperative attributes. In their research, they found that environment also influence the e-commerce adoption.

In the TOE framework, environmental context refers to the arena where the organizations do the business. Mangula et al [20] also stated that IT innovations do not accomodate only for an internal audience, but also to the company's customers, suppliers, and business partners. As similar with Molla and Licker study's [19], Ramdani et al [20] and Ghobakhloo et al [15] also found that environmental context significantly influence the e-commerce adoption. Thus, based on previous studies above, the following hypothesis is stated:

H3: Environmental context has significant influnce on the adoption of e-tourism by companies.

\section{Research Method}

This study empirically examine the influence of technological, organizational, and environmental towards adoption cluster, quantitative technique had been designed to address on research questions. Electronic survey method was used to collect data by distributing questionnaires using my $3 q$ website hosted. The tourism companies in Bali are the population of this research. Additionally, the sample selection was done by using non-probability sample technque, referred to convenience sampling. Therefore, 394 companies have been contacted to anticipate the questionnaires. The Assoctiation of Indonesian Tour and Travel Agency (ASITA) and Perhimpunan Hotel dan Restoran Indonesia (PHRI) of Bali already contributed the data collection by filling out the questionnaires from these links: http://my3q.com for the member of ASITA Bali and PHRI Bali. The numbers of questionnaires that can be analysed are 91 companies.

Adoption cluster as dependent variable was classified on five groups of website chracteristics, including the adoption of e-mail, web presence, prospecting, transactions or business online integration, and links which consist of 19 items based on Teo and Pian's study [12]. The classification of adoption cluster was employed by using cluster adoption through mean value of website features on each firm. Independent constructs of TOE formed three variables including technological, organizational, and environmental aspects were measured on a-Likert five point scale. Each variable of TOE framework forms three dimensions adopted from Ghobakhloo et al [15] and Gobakhloo and Tang [6]. Technological aspect consists of perceived benefit, cost, and compatibility; organizational was measured by the intensity of information, the conversance of CEO, and CEO's newfangledness. Furthermore, technology 
merchants, customer or supplier pressure, and competition represent the environmental aspect. Therefore, totally 33 indicators were employed in TOE's construct.

Testing the measurement model was conducted to determine the extent to which indicators represent a given theoritical concept and to ensure the robustness of data. This research used formative indicators on each variables of TOE construct. Consequently, validity testing through convergent and discriminant validity also composite reliability to test reliability was not being a pa,rt of measurement model testing (outer model). Formative measurement only validated data based on the value of outer weights, since there is no correlation among indicators [22][23]. Additionally, according to Diamantopoulos [24], formative construct comprised distinct aspects which are not necessary to correlate amongst each other. Data analyzed using smartPLS software through formative measurement model. Bootstrapping process results the value of significance level based on T-statistics value to examine the proposed hypothesis.

\section{Results and Discussions}

\subsection{Cluster Classification}

Cluster classification in this study was conducted by analysing the value of the average of each cluster presented. Adoption websites of 91 companies in the tourism industry in Bali (etourism) in this study were divided into five clusters according to the research of Teo and Pian [12]. Cluster determination from each company analyzed through the average value of each cluster as a whole. Cluster classification is determined by rounding the average rate to above value [12]. Table 1 shows the distribution of clusters of 91 companies that were being respondent to this study.

Table 1 shows that the majority of the companies surveyed in this study are included in the classification of clusters 3 and 4 levels. Based in features in adopting the website, companies engaged in the tourism industry in Bali have the complete website features such as a contact number via e-mail, information about the company including the products or services offered, searching menu, but also provide customer service to build the opportunity for visitors to respond or give a feedback for the company. This can be evidnetly seen when company not only facilitates cinsumers to make reservations or marketing but also electronic paymentseven eqipped with integrarion or communication between consumers and suppliers. Consequently, $13.19 \%$ of these companies even provide links to other websites.

Table 1. Cluster by Category

\begin{tabular}{|c|l|c|c|}
\hline Cluster & \multicolumn{1}{|c|}{ Category } & No. of Firm & $\begin{array}{c}\text { Percentage } \\
(\%)\end{array}$ \\
\hline 1 & Contact Method & 1 & 1.10 \\
\hline 2 & Informations & 16 & 17.58 \\
\hline 3 & Customer Service & 31 & 34.07 \\
\hline 4 & Transaction & 31 & 34.07 \\
\hline 5 & $\begin{array}{l}\text { Links } \\
\text { (Transformation) }\end{array}$ & 12 & 13.19 \\
\hline \multicolumn{2}{|l|}{ Total } & 91 & 100 \\
\hline
\end{tabular}




\subsection{Formative (Outer Model)}

This research uses formative measurement model. Validity test of formative inndicators refers to the importance of each indicators defined the construct. Validity testing was employed by using smartPLS program through bootstrapping process to calculate outer weights score. Based on Hair et al. [23], there is rule of thumb for the significance value of outer weights based on T-Statistics, which should greater than 1.64 at 0.10 of significant level. However, this study did not eliminate insignificant indicators in order to avoid the changing of theoritical perspective [25].

Indicators on each dimension of the TOE's formative construct shows that not all of the indicators have T-statistic values more than 1.64 (two-tailed tests of significance levels > $0.10)$. By looking at the value of the T-statistic on the outer weight output, several indicators on the construct formative tested insignificant or does not meet the validity testing. The value of T-statistic on outer weight output shows that some of the indicators that are invalid are not indicators measuring the dimensions and variables. Therefore, they are not valid to measure the construct of TOE (Technological, Organizational, and Environmental) statistically. This study also did not carry out the reliability testing because each indicator in a latent variable is assumed to be correlated. Accordingly, the reliability testing is not necessity to be measured [23].

According to Hartono and Abdillah [25], "If the formative constructs do not meet the criteria of construct validity testing (one or more indicators are not significant), then the formative construct statistically cannot be tested further in the structural model. However, removing a formative construct of a research model led to the loosing of its meaning and do not appropriate with the study purpose, then the researcher should maintain these formative constructs in order to examined further in the structural model". Based on this statement, in order that hinder the deviation of the reserach purpose theoritically, the researcher decided not to drop the indicators which are invalid. Hence, this study still engages all of the indicators to test the structural model.

\subsection{Bootstrapping (Inner Model)}

Structural model consists of latent construct which cannot be observed. This test contains the estimation of path coefficients that identify the strength of the relationship between dependent and independent variables. Testing of structural models generate significant path value of the relationship between latent variable by using the function of bootstrapping. Ghozali [26] stated that reflective constructs of structural model need to be evaluated by using the R-square for the dependent construct, which indicates the value of the impact of numerous independent latent variables on the dependent latent variables.

This study uses a formative construct. Therefore, the structural model testing was done by roughly calculating the path coefficient to assess the level of significance of each hypothesis. SmartPLS 2.0 M3 program was established to examine a formative inner model for this study. Path coefficient processing results in the form of statistical value and the amount of the original sample can be seen in the following table 2 .

Table 2 illustrates that the environmental effects towards the cluster adoption is positive (0.462115) and significant at $\alpha=0.10$ (two-tailed test) with the statistical value of 3.997701 > 1.64 (in bold). Variable organization negatively affect the adoption of cluster is positive 
(0.295529) and were significant at $\alpha=0.10$ (two-tailed test) with the statistical value of $2.287575>1.64$.

Table 2. The Path Coefficients (Mean, STDEV, T-Values)

\begin{tabular}{|c|c|c|c|c|}
\hline & $\begin{array}{c}\text { Sample } \\
\text { (mean) }\end{array}$ & $\begin{array}{c}\text { Standard } \\
\text { Deviation } \\
\text { (STDEV) }\end{array}$ & $\begin{array}{c}\text { Standard } \\
\text { Error } \\
\text { (STERR) }\end{array}$ & $\begin{array}{c}\text { T Statistics } \\
\text { (|O/STERR|) }\end{array}$ \\
\hline ENVI->ADOP & 0.414332 & 0.115595 & 0.115595 & $\mathbf{3 . 9 9 7 7 0 1}$ \\
\hline ORG->ADOP & 0.004163 & 0.128354 & 0.128354 & 0.725961 \\
\hline TEC->ADOP & 0.321128 & 0.129189 & 0.129189 & $\mathbf{2 . 2 8 7 5 7 5}$ \\
\hline
\end{tabular}

Based on the significance of paths amongst, the constructs in the structural model according to T-statistic value in Table 2 above, the results of hypothesis testing conclusions as a whole is shown in Table 3.

Table 3. Hypothesis Testing

\begin{tabular}{|l|l|l|}
\hline Hypothesis & Hypothesis Statement & Result \\
\hline H1 & $\begin{array}{l}\text { Technological significantly influence } \\
\text { towards adoption cluster }\end{array}$ & Supported* \\
\hline H2 & $\begin{array}{l}\text { Organizational significantly influence } \\
\text { towards adoption cluster }\end{array}$ & Not Supported* \\
\hline $\mathbf{H 3}$ & $\begin{array}{l}\text { Environmental significantly influence } \\
\text { towards adoption cluster }\end{array}$ & Supported* \\
\hline
\end{tabular}

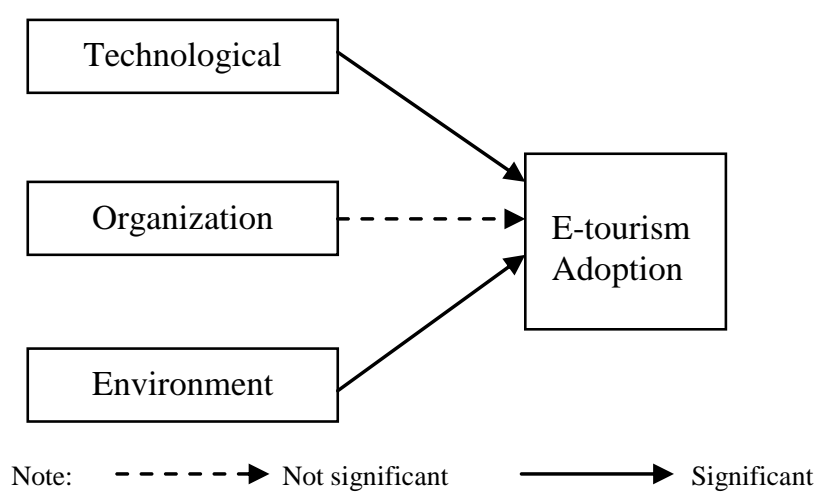

Figure 1. Research Model (Bootstrapping Output)

The resulth of path coefficient value after testing the research model through bootsrapping process. Based on the research model above, it can be seen that smartPLS 2.0 M3 run overall four variables (technological, organizational, environmental, and cluster adoption). Variable of technological aspect that consists of three dimensions: perceived benefir, cost, and 
compatibility shows that the dimensions of perceived benefir have the greatest influence in defining the technology variables. It implies that the company tourism in Bali perceived that th e use of the website can provide many advantages in their businesses, such as the availability of timely information, improving the performance, profits and productivity, increasing serendipity, as well as enabling the company to carry out promotional and better marketing. Furthermore, costs of use, maintenance, and training are likely not provide a significant impact to the cluster adoption for tourism enterprises in Bali. As well as the suitability of website adoption with the company's value, the work of employees, legal policy and consumer needs are not being aspects to consider in utilizing the company's website. The result conformed to Pearson and Grandon [27], Ghobakhloo et al.[15], and Ramdani et al. [17], who describe the perceived benefit as the most decisive enabler in adopting website because it improves the company's performance and expand marketing opportunities.

Organizational aspect in this study significantly did not affet the level of cluster adoption. In terms of firm views on organizational aspect, respondents believed that the dimensions of information intensity, the conversance of CEO, and the newfangledness of CEO were not able to be a factor that encourages the increasing rate of website adoption, although statistically information intensity and the CEO'S innovativeness dimensions have a significant value of Tstatistic. However, low influence of the CEO's knowledge in driving the adoption of the website indicates that high or low the understanding of CEO in adopting the website is not able to push the company to complement the features of the website. This is relevant with the previous study that hasd been conducted by Ghobakhloo et al. [15] which states that the knowldege of CEO and his or her experience was not found to affect the website adoption by SMEs.

Website adoption has been recognized not only defined by technological aspect but also environmental aspect. Environment variables formed by the dimensions of supports from technology vendors, customer or supplier's pressure, and competition. The competition factor determines the level of the company in adopting a website. Interestingly, the provision of information which can be accessed 24 hours directly anytime and anywhere by consumers makes the company seeks to provide a more complete website features within serving their potential customers. This intense competition forced by the widespread availability of information through the Internet. Therefore, it can be easier for consumers to find information quickly when they intent to access the product or service of the company's competitiors. However, pressure from consumers or suppliers and support from technology merchants do not become factors shaping influence on the envrionmental aspects of the webstite adoption level. Website adoption in SME, influenced by the company's desire to maintain their innovation referred to MacKay et al. [28], Pearson and Grandon [27], Al-Qirim [29] and Oliveira and Martins [30].

\section{Conclusion}

Website utilization has a great impact on enhancing the number of tourist visitors in developing countries like in Indonesia. This study resulted that the technological and environmental aspects are being the most important factors towards e-tourism adoption decision behavior for tourism enterprises in Bali. Consequently, dominant percentage of website adoption level which showed in the cluster of prospecting and transactions implies that website characteristics of tourism companies in Bali should actualized their advantage by attract consumers to visit their website and making orders or transactions. It will be happened 
if a company provided a timely information, friendly features, and quick response of customer service.

Since more and more firms attempt to develop their innovative website, not only technological and environmental factors but also various aspects through longitudinal study can be seen as an enabler to influence the website adoption for further work. In order to gain their competitive advantage, owner or manager should be aware to build innovative features of website. Adcance researches also nee to assess redudancy analysis and collinearity testing to evaluate emprically the formative outer models.

\section{Acknowledgment}

The Authors are grateful to Minister of Indonesian Higher Education and Technology Research (RistekDikti) who giving the financial support of this research as MP3EI grant in 2016.

\section{References}

[1] Crnojevac, Igor H., Jadranka, G., and Sasa, K.: E-Tourism: A Comparison of Online and Offline Bookings and the Importance of Hotel Attributes. JIOS. Vol. 34. No. 1 (2010).

[2] Buhalis, D. and Jun, S. H.: E-Tourism. Contemporary Tourism Reviews [Online]. Available HTTP: http://www.goodfellowpublishers.com/free_files/fileEtourism.pdf (accessed on 10 November 2015) (2011)

[3] Karanasios, Stan., and Burgess, Stephen: Tourism and Internet Adoption. International Journal of Tourism Research. 10:169-182 (2008)

[4] Dargah, D.Bagheri., and Golrokhsari, Hamed: E-tourism and Customer Satisfaction Factors. International Journal of Advances in Management Science, 2012, 1:35-40 (2012).

[5] Rahayu, R., and Day, J.: Determinants Factors of E-Commerce Adoption by SMEs in Developing Country: Evidence from Indonesia. Social and Behavioral Sciences 195:142-150 (2015).

[6] Ghobakhloo, M. And Tang, S.H.: The Role of Owner/Manager in Adoption of Electronic Commerce in Small Business: The Case of Developing Countries. Journal of Small Business and Enterprise Development. Vo. 20, No. 4, p 754-787 (2013).

[7] Gunawan, Myra and Ortis, Oliver.: Strategic Plan: Sustainable Tourism and Green Jobs for Indonesia. Jakarta: International Labour Organization (2012).

[8] Tornatzky, L. G., Fleischer, M., and Chakrabarti, A. K.: The Processes of Technological Innovation (eds). Lexington, MA: Lexington Books (1990).

[9] Nurhadi., N. U., Syafi'ie, I. M. and Utami, H. N.: Antecedents of E-Commerce Use in the Hospitality Industry: An Empiricsl Study in Indonesia. European Journal of Business and Management. Vol. 7, No. 11 (2015).

[10] Al-Somali, Sabah, A., Roya, G., and Ben, C.: A Stage-oriented Model (SOM) for Ecommerce Adoption: A Study of Saudi Arabian Organizations. Journal of Enterprise Information Management, Vol. 28, Iss. 3:326-345 (2015).

[11] Salwani, Mohamed. I, Marthandan, G., Norzaidi, Mohd. Daud., and Chong, S. Choy.: E-Commerce Usage and Business Performance in the Malaysian Tourism Sector: Empirical Analysis. Journal of Information Management and Computer Security. Vol. 17, No. 2:166-185 (2008).

[12] Teo, T. S. H., and Pian, Y.: A Model for Web Adoption. Information and Management, 41:457-468 (2004).

[13] Rogers, E. M.: Diffusion of Innonvations. The Free Pres: New York, NY (1995).

[14] Buhalis, D. and Deimezi, O.: Information Technology Penetration and Ecommerce Developments in Greece, with a Focus on Small and Medium-sized Enterprises. Electronic Markets, Vol. 13, No. 4:309324 (2003).

[15] Ghobakhloo,, Morteza., Aranda, Daniel A., and Amado, Jose B.: Adoption of E-Commerce Applications in SMEs. Industrial Management \& Data Systems. Vol. 111, No. 8:1238-1269 (2011). 
[16] Oliveira, T and Martins, M. F.: Literature Review of Information Technology Adoption Model at Firm Level. Electronic Journal Information Systems Evaluation. Vol. 14, Iss. 1 (2011).

[17] Ramdani, B., Cheevers, D., and Williams, D. A.: SME's Adoption of Enterprise Applications. A Technology -Organization-Environment Model. Journal of Small Business and Enterprise Development. Vol. 20, No. 4:735-753 (2013).

[18] Molla, A., and Licker, P. S.: E-Commerce Adoption in Developing Countries: A Model and Instrument. Informantion and Management. Vol. 42, No. 6:877-899 (2005).

[19] Molla, A., and Licker, P. S.: Perceived E-Readinesa Factors in E-Commerce Adoption: An Empirical Investigation in a Developing Country. International Journal of Electronic Commerce. Vol. 10, No. 1:83-110 (2005).

[20] Mangula, L. S., Weerd, L. V., and Brinkkemper, S.: The Adoption of Software-as-a-service: An Indonesian Case Study. The 18th Pacific Asia Conference on Information System (PACIS 2014), 1-17 (2014).

[21] Awa, Hart, O., Ojiabo, Ojiabo, U., and Emecheta, Bartholomew, C.: Integrating TAM, TPB, and TOE Frameworks and Expanding Their Characteristic Constructs for E-Commerce Adoption vy SMEs. Journal of Science \& Technology Policy Management, Vol 6, Iss 1:76-94 (2015).

[22] Chin, W.: Issues and Opinion on Structural Equation Modeling. MIS Quarterly. 22(1):7-16 (1998).

[23] Hair, J., Hult, G., Ringle, C., and Sarstedt, M.: A Primer on Partial Least Square Structural Equation Modelling (PLS-SEM). CA: Sage (2014).

[24] Diamantopoulos, A. Incorporating Formative Measures into Covariance-based Structural Equation Models. MIS Quarterly, 35, 335-358 (2011).

[25] Hartono, J., \& Abdillah, W.: Concept and Application of PLS (Partial Least Square for Empirical Research. Yogyakarta: BPFE (2009).

[26] Ghozali, Imam.: Structural Equation Modelling Alternative Method with Partial Least Square (PLS). Semarang: Diponegoro University (2008).

[27] Pearson, J. M. and Grandon, E. E.: An Empirical Study of Factors that Influence E-Commerce Adoption/Non-Adoption in Small and Medium-suzed Business. Journal of Internet Commerce. Vol. 4, No. 4:1-21 (2006).

[28] MacKay, N., Parent, M. and Gemino: A Model of Electronic Commerce Adoption by Small Voluntary Organizations. European Journal of Information Systems. Vol. 13, No. 2:147-159 (2004).

[29] Al-Qirim, N.: The Adoption of eCommerce Communications and Applications Technologies in Small Business in New Zealand. Electronic Commerce Research and Applications, Vol. 6, No. 4:462-73 (2007).

[30] Oliveira, T and Martins, M. F.: Understanding E-Business Adoption Across Industries in European Countries, Industrial Management and Data Systems, Vol. 110, No. 9:1337-1354 (2010). 